\title{
RANCANGAN SISTEM MULTI ITEM SINGLE SUPPLIER SEBAGAI PENGENDALI JUMLAH DAN FREKUENSI PEMESANAN BEBERAPA BAHAN BAKU UNTUK MEMINIMASI TOTAL BIAYA PERSEDIAAN (STUDI KASUS DI PT. X)
}

\author{
Abdul Azis Syarif ${ }^{1 *}$, Budi Santri Kusuma ${ }^{2 *}$ \\ ${ }^{1}$ Program Studi Teknik Industri, Fakultas Teknik Universitas Al Azhar Medan \\ Jl. Pintu Air IV No.214, Kwala Bekala, Medan, Sumatera Utara- 201422 \\ ${ }^{2}$ Program Studi Teknik Industri, Fakultas Teknik Universitas Medan Area \\ Jl. Kolam 1, Medan Estate, Medan, Sumatera Utara 20000 \\ Email : *abdulaziz75132@gmail.com
}

\begin{tabular}{l} 
Artikel Info \\
\hline Artikel Historis : \\
Terimaranaris 25 Februari 2021 \\
Terima dan direvisi 26 Februari \\
$2021 \quad 16$ April 2021 \\
Disetujui $\quad$ Kata Kunci : Persediaan, \\
Economic Order Quantity, \\
Economic Order Interval, Multi- \\
Item Single Supplier
\end{tabular}

Keywords : Inventory, Economic Order Quantity, Economic Order Interval, Multi-Item Single Supplier

\begin{abstract}
Abstrak
Pengendalian persediaan dibutuhkan untuk melancarkan proses produksi, memaksimalkan kepuasan konsumen dan meminimasi biaya pengadaan persediaan. Penelitian ini membahas sistem pengendalian bahan baku surat kabar yaitu kertas dan plate dengan menggunakan metode Multi Item Single Supplier, dimana bahan bakunya berasal dari supplier yang sama sehingga pemesanan dilakukan secara bersamaan agar dapat meminimasi biaya total yang dikeluarkan dari perusahaan. Metode Multi Item Single Supplier digunakan untuk mengetahui jumlah pemesanan bahan baku, frekuensi pemesanan, interval pemesanan dan total biaya persediaan untuk beberapa bahan baku yang berasal dari satu supplier. Penelitian ini menunjukkan bahwa dengan metode Multi Item Single Supplier perusahaan dapat menurunkan total biaya persediaan sebesar 36,2\% hingga 38,7\% dibandingkan dengan total biaya persediaan aktual perusahaan sebelumnya. \footnotetext{
Abstract

PT. $X$ is a company engaged in the loading and unloading company $(P B M)$. In observations, the placement of products in the warehouse is still not organized or is still not neat in making the product preparation, resulting in the absence of work efficiency in moving products from the warehouse to the seventh product of the company to the destination company. The problems faced by this company are irregular in arranging products that enter the warehouse and result in inefficient storage in the warehouse and slowing down the forklift mileage. The amount of area required for each product is not in accordance with the time of storage and delivery of the product in the warehouse, which causes additional material handling costs and can reduce the performance of the system first in first out (FIFO). Spacing between piles that are too close results in product damage. The method used in warehousing processing is shared storage where products that have the most delivery frequencies and which are often in and out are brought close to the entrance to minimize material handling transfer distance. The results of the shared storage approach can minimize the closest mileage of $3.6 \mathrm{~m}$ and the furthest $86 \mathrm{~m}$.
} 


\section{JURNAL ILMIAH TEKNIK MESIN, INDUSTRI, ELEKTRO DAN SIPIL}

Rancangan sistem multi item single supplier sebagai pengendali jumlah dan frekuensi pemesanan beberapa bahan baku untuk meminimasi total biaya persediaan

(studi kasus di pt. $x$ )

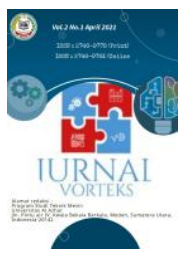

\section{PENDAHULUAN}

Salah satu permasalahan yang sering dihadapi perusahaan adalah mengenai pengelolaan persediaan bahan baku, dimana di dalam penanganannya tidak dilakukan dengan baik, maka akan menimbulkan kerugian yang cukup besar bagi perusahaan. Tujuan dari pengendalian persediaan adalah untuk menekan biaya operasional seminimal mungkin untuk mengoptimalkan kinerja perusahaan [1].

Persediaan adalah material yang disediakan pada saat keadaan menunggu baik penjualan dimasa yang akan datang maupun yang akan mengalami transformasi. Persediaan dapat berupa bahan baku (material), produk setengah jadi, maupun produk jadi yang siap untuk dijual, didistribusikan, atau disimpan [2]. Jumlah persediaan bahan baku dipengaruhi oleh kebutuhan baku Kurangnya persediaan bahan baku akan mengakibatkan terhambatnya proses produksi sehingga tidak terpenuhinya permintaan konsumen, sedangkan persediaan bahan baku yang terlalu banyak akan menaikkan biaya pengadaan persediaan, oleh sebab itu, pengendalian persediaan dibutuhkan untuk melancarkan proses produksi, memaksimalkan kepuasan konsumen, dan meminimasi biaya pengadaan persediaan.

Masalah persediaan juga dialami oleh PT. X yang merupakan salah satu perusahaan penerbitan yang menghasilkan surat kabar seperti Metro 24 jam, Pos Metro Medan, dan Sumut Pos. Seiring dengan kemajuan teknologi kebutuhan masyarakat akan informasi meningkat pula [3]. Sehingga permintaan akan bahan cetakan untuk memproduksi Koran juga semakin meningkat. Perusahaan harus menyiapkan bahan baku untuk mengantisipasi peningkatan permintaan tersebut.

Pada tahun 2014 perusahaan melakukan pemesanan bahan baku kertas dan plate yang dapat dilihat pada tabel 1

Tabel 1. Tabel pemesanan/kebutuhan bahan baku

Bulan Bahan Baku

\begin{tabular}{lcc}
\hline & Kertas (rol) & $\begin{array}{c}\text { Plate } \\
\text { (Lembar) }\end{array}$ \\
\hline Januari & 110,1 & 1000 \\
\hline Februari & 114,4 & 1100 \\
\hline Maret & - & 1000 \\
\hline April & 119 & 1100 \\
\hline Mei & 125,3 & 800 \\
\hline Juni & - & 700 \\
\hline Juli & 115,4 & 800 \\
\hline Agustus & 179,9 & 900 \\
\hline September & - & 500 \\
\hline Oktober & 140,5 & 700 \\
\hline November & 163,7 & 800 \\
\hline Desember & 445,2 & 1000 \\
\hline Jumlah & 1513,5 & 10400 \\
\hline
\end{tabular}

\section{METODE PENELITIAN}

Jenis penelitian ini adalah studi kasus (case study) merupakan suatu penelitian yang dilakukan secara intensif, terinci dan mendalam terhadap suatu organisasi, lembaga atau gejala tertentu.[4] Pemilihan metode penyelesaian masalah dalam penelitian ini adalah dengan menggunakan metode multi item single supplier.

\section{PENGUMPULAN DAN PENGOLAHAN DATA}

Pengumpulan data adalah tahapan yang dilalui sebelum penelitian dilakukan, data yang dikumpulkan tersebut akan dijadikan input dalam pengolahan data dan urutan pengumpulan data sebagai berikut :

1. Data biaya pesan dan biaya simpan.

Data biaya pesan dan biaya simpan dapat dilihat pada tabel 2 dan 3 berikut :

Tabel 2 Komponen biaya Pemesanan kertas dan plate 


\section{JURNAL ILMIAH TEKNIK MESIN, INDUSTRI, ELEKTRO DAN SIPIL}

Rancangan sistem multi item single supplier sebagai pengendali jumlah dan frekuensi pemesanan beberapa bahan baku untuk meminimasi total biaya persediaan

(studi kasus di pt. $x$ )

\begin{tabular}{cccc}
\hline No & $\begin{array}{c}\text { Kompone } \\
\text { n Biaya }\end{array}$ & \multicolumn{2}{c}{ Bahan Baku } \\
\cline { 3 - 4 } & & $\begin{array}{c}\text { Kertas } \\
\text { (Rp/pesana } \\
\text { n) }\end{array}$ & $\begin{array}{c}\text { Plate } \\
\text { (Rp/pesana } \\
\text { n) }\end{array}$ \\
\hline $\mathbf{1}$ & $\begin{array}{c}\text { Biaya } \\
\text { Telepon }\end{array}$ & 3.000 & 3.000 \\
\hline $\mathbf{2}$ & $\begin{array}{c}\text { Biaya } \\
\text { Administra } \\
\text { si }\end{array}$ & 27.444 & 20.583 \\
& & \\
\hline $\mathbf{3}$ & $\begin{array}{c}\text { Biaya } \\
\text { Tenaga } \\
\text { Kerja }\end{array}$ & 40.000 & 40.000 \\
\hline $\mathbf{4}$ & $\begin{array}{c}\text { Biaya } \\
\text { Bongkar } \\
\text { Muat }\end{array}$ & 2.102 .500 & 2.166 .750 \\
\hline \multirow{3}{}{ Total } & 2.172 .944 & 2.230 .333 \\
\hline
\end{tabular}

Tabel 3. Komponen Biaya Penyimpanan Bahan Baku

\begin{tabular}{cccc}
\hline No & Kompon & \multicolumn{2}{c}{ Bahan Baku } \\
\cline { 3 - 4 } & en Biaya & $\begin{array}{c}\text { Kertas } \\
\text { (Rp/rol/p } \\
\text { esanan) }\end{array}$ & $\begin{array}{c}\text { Plate } \\
\text { (Rp/lembar/ } \\
\text { pesanan) }\end{array}$ \\
\hline $\mathbf{1}$ & $\begin{array}{c}\text { Biaya } \\
\text { Listrik }\end{array}$ & 8.484 & 1.818 \\
\hline $\mathbf{2}$ & $\begin{array}{c}\text { Biaya } \\
\text { Tenaga } \\
\text { Kerja } \\
\text { dan } \\
\end{array}$ & 22.980 & 4.924 \\
& & \\
\hline & Pengawa \\
s gudang & & \\
\hline & & \\
\hline & & \\
\hline
\end{tabular}

2. Lead Time Pemesanan Bahan Baku

Waktu tunggu pengadaan bahan baku adalah waktu yang dibutuhkan sejak bahan baku dipesan sampai dengan bahan baku tersebut sampai di perusahaan [5]. Berdasarkan informasi dari perusahaan, waktu tunggu untuk bahan baku adalah 7 hari, meliputi saat bahan baku dipesan kepada supplier, pemesanan diterima, persiapan bahan baku, bahan baku dikirim dan sampai bahan baku tiba digudang.
3. Data aktual persediaan bahan baku.

Data Aktual persediaan bahan baku dapat dilihat pada tabel 4 dan tabel 5 berikut :

Tabel 4. Persediaan Bahan Baku Kertas

\begin{tabular}{|c|c|c|c|}
\hline \multirow[t]{2}{*}{ Bulan } & \multicolumn{3}{|c|}{ Bahan Baku Kertas (Rol) } \\
\hline & $\begin{array}{c}\text { Persedia } \\
\text { an }\end{array}$ & $\begin{array}{c}\text { Pemakai } \\
\text { an }\end{array}$ & $\begin{array}{c}\text { Total } \\
\text { Persedia } \\
\text { an Akhir }\end{array}$ \\
\hline Januari & 574 & 124,9 & 449,1 \\
\hline Februari & 563,5 & 114,6 & 448,8 \\
\hline Maret & 448,8 & 137,9 & 310,9 \\
\hline April & 430 & 141,2 & 288,8 \\
\hline Mei & 414,1 & 140,8 & 273,2 \\
\hline Juni & 273,2 & 153,8 & 119,4 \\
\hline Juli & 234,8 & 136,4 & 98,4 \\
\hline Agustus & 278,4 & 135,8 & 142,6 \\
\hline $\begin{array}{c}\text { Septemb } \\
\text { er }\end{array}$ & 142,6 & 130,4 & 12,2 \\
\hline Oktober & 152,7 & 148,7 & 4 \\
\hline $\begin{array}{c}\text { Novemb } \\
\text { er }\end{array}$ & 167,7 & 137 & 30,7 \\
\hline $\begin{array}{c}\text { Desembe } \\
\mathbf{r}\end{array}$ & 475,9 & 124,9 & 351 \\
\hline Jumlah & 4155,6 & 1626,3 & 2529,3 \\
\hline $\begin{array}{l}\text { Rata- } \\
\text { rata }\end{array}$ & 346,3 & 180,7 & 210,8 \\
\hline
\end{tabular}




\section{JURNAL ILMIAH TEKNIK MESIN, INDUSTRI, ELEKTRO DAN SIPIL}

Rancangan sistem multi item single supplier sebagai pengendali jumlah dan frekuensi pemesanan beberapa bahan baku untuk meminimasi total biaya persediaan

(studi kasus di pt. $x$ )

Tabel 5. Persediaan Bahan Baku Plate

\begin{tabular}{cccc}
\hline Bulan & \multicolumn{3}{c}{ Bahan Baku Plate (Lembar) } \\
\cline { 2 - 4 } & $\begin{array}{c}\text { Persedia } \\
\text { an }\end{array}$ & $\begin{array}{c}\text { Pemakai } \\
\text { an }\end{array}$ & $\begin{array}{c}\text { Total } \\
\text { Persedia } \\
\text { an Akhir }\end{array}$ \\
\hline Januari & 1243 & 700 & 543 \\
\hline Februari & 1643 & 760 & 883 \\
\hline Maret & 1883 & 780 & 1103 \\
\hline April & 2203 & 1112 & 1091 \\
\hline Mei & 1891 & 798 & 1093 \\
\hline Juni & 1793 & 790 & 1003 \\
\hline Juli & 1803 & 810 & 993 \\
\hline Agustus & 1893 & 870 & 1023 \\
\hline $\begin{array}{c}\text { Septemb } \\
\text { er }\end{array}$ & 1523 & 760 & 763 \\
\hline Oktober & 1463 & 760 & 703 \\
\hline $\begin{array}{c}\text { Novemb } \\
\text { er }\end{array}$ & 1503 & 790 & 713 \\
\hline $\begin{array}{c}\text { Desembe } \\
\text { r }\end{array}$ & 1713 & 987 & 726 \\
\hline \begin{tabular}{c} 
Jumlah \\
\hline
\end{tabular} & 20554 & 9917 & 10637 \\
\hline
\end{tabular}

Dari hasil pengumpulan dan pengolahan data, dapat dihitung biaya persediaan bahan baku :

\section{Bahan Baku Kertas}

$\mathrm{F}=$ Frekuensi Pemesanan $=9$ kali

$\mathrm{D}=$ Persediaan Rata-rata per tahun $=210,8 \mathrm{Rol}$

$\mathrm{S}=$ Biaya pesan per pesanan $=\mathrm{Rp} .2 .171 .944$

$\mathrm{H}=$ Biaya Simpan per rol per tahun $=\mathrm{Rp} .31 .464$

Sehingga :

Biaya pesan per tahun :

$\mathrm{S}=9$ X Rp. 2.172.944 = Rp. 19.556.496 per tahun

Biaya Simpan Per Tahun :

$\mathrm{H}=210,8$ X Rp. $31.464=$ Rp. 6.632.611,4

Total Inventory Cost :

$\mathrm{TIC}=\mathrm{Rp} .19 .556 .496+\mathrm{Rp} .6 .632 .611,4$

$$
=\text { Rp. 26.189.107,4 }
$$

\section{Bahan Baku Plate}

$\mathrm{F}=$ Frekuensi Pemesanan $=12 \mathrm{kali}$
$\mathrm{D}=$ Persediaan Rata-rata per tahun $=1181,9$ lembar

$\mathrm{S}=$ Biaya pesan per pesanan $=\mathrm{Rp} .2 .230 .333$

$\mathrm{H}=$ Biaya Simpan per lembar per tahun $=\mathrm{Rp}$. 6742

Sehingga :

Biaya pesan per tahun :

$S=12 X$ Rp. 2.230.333 = Rp. 26.763.996 per tahun

Biaya Simpan Per Tahun :

$\mathrm{H}=1181,9$ X Rp. $6742=$ Rp. 7.968.369,8

Total Inventory Cost :

$\mathrm{TIC}=$ Rp. $26.763 .996+$ Rp. 7.968.369,8 $=$ Rp. 34.732.365,8

Dari hasil perhitungan di atas, biaya persediaan berdasarkan kondisi aktual perusahaan dapat dilihat pada tabel berikut :

Tabel 6. Total Biaya Persediaan berdasarkan kondisi aktual perusahaan

\begin{tabular}{cccc}
\hline No & Komponen & \multicolumn{2}{c}{ Bahan Baku } \\
\cline { 3 - 4 } & Biaya & $\begin{array}{c}\text { Kertas } \\
\text { (Rp/tahun) }\end{array}$ & $\begin{array}{c}\text { Plate } \\
\text { (Rp/tahun) }\end{array}$ \\
\hline $\mathbf{1}$ & Biaya & 19.556 .496 & 26.763 .996 \\
& Pemesanan & & \\
\hline $\mathbf{2}$ & Biaya & 6.632 .611$, & 7.968 .369$, \\
& Penyimpan & 4 & 8 \\
& an & & \\
\hline $\mathbf{3}$ & Total Biaya & 26.189 .107 & 34.732 .365 \\
& Persediaan &, 4 &, 8 \\
\hline
\end{tabular}

Sehingga biaya total untuk bahan baku kertas dan plate sebagai berikut :

Biaya Total $=$ Rp.26.189.107,4 + 34.732.365.8

$$
=\text { Rp. 60.921.473,2/tahun }
$$

\section{Economic Order Quantity (EOQ)}

Menentukan frekuensi optimal $\left(\mathrm{m}^{*}\right)$

$\mathrm{m}^{*}=\sqrt{\frac{(H 1 R 1)+(H 2 R 2)}{2 \times(C 1+C 2)}}$

Keterangan notasi :

$\mathrm{H}_{1}=$ Biaya simpan bahan baku kertas per unit per tahun

$\mathrm{H}_{2}=$ Biaya simpan bahan baku plate per unit per tahun

$\mathrm{R}_{1}=$ Jumlah pemesanan bahan baku kertas per tahun

Hal 56 dari 58 


\section{JURNAL ILMIAH TEKNIK MESIN, INDUSTRI, ELEKTRO DAN SIPIL}

Rancangan sistem multi item single supplier sebagai pengendali jumlah dan frekuensi pemesanan beberapa bahan baku untuk meminimasi total biaya persediaan

(studi kasus di pt. $x$ )

$\mathrm{R}_{2}=$ Jumlah pemesanan bahan baku plate per tahun

$\mathrm{C}_{1}=$ Biaya Pemesanan bahan baku kertas setiap kali pesan

$\mathrm{C}_{2}=$ Biaya Pemesanan bahan baku plate setiap

kali pesan

$\mathrm{P}_{1}=$ Biaya pembelian kertas

$\mathrm{P}_{2}=$ Biaya pembelian plate

Sehingga frekuensi optimalnya adalah :

$$
\begin{aligned}
& \mathrm{m}^{*}=\sqrt{\frac{(R p .31 .464 \times 1513,5)+(\mathrm{Rp} .6 .742 \times 10400)}{2 \times(R p .2 .172 .944+\mathrm{Rp} .2 .230 .333) .}} \\
& =3,6=4 \mathrm{kali}
\end{aligned}
$$

a. Menentukan jumlah sekali pesan item I

$\left(\mathrm{Q}_{\mathrm{i}}\right)$

$\mathrm{Q}_{\mathrm{i}}=\frac{R i}{m *}$

Kertas

$\mathrm{Q}_{1}=\frac{1513,5}{4}=378,375 \mathrm{rol}$

Plate

$\mathrm{Q}_{2}=\frac{10400}{4}=2600$ lembar

\section{Economic Order Interval (EOI)}

Menentukan Interval Waktu pemesanan optimal $\left(\mathrm{T}^{*}\right)$

$\mathrm{T}^{*}=\sqrt{\frac{2 x(C 1+C 2)}{(H 1 R 1)+(H 2 R 2)}}$

$=\sqrt{\frac{2 x(R p .2 .172 .944+\mathrm{Rp} .2 .230 .333)}{(R p .31 .464 \times 1513,5)+(\mathrm{Rp} .6 .742 \times 10400)}}$

$=0.274$ tahun

Menentukan jumlah sekali pesan item I $\left(\mathrm{Q}_{\mathrm{i}}\right)$

$\mathrm{Qi}=\mathrm{R}_{\mathrm{i}} \cdot \mathrm{T}^{*}$

Kertas

$\mathrm{Q}_{1}=\mathrm{R}_{1} . \mathrm{T}^{*}$

$=1513,5 \cdot 0.274=414,699 \mathrm{rol}$

Plate

$\mathrm{Q}_{2}=\mathrm{R}_{2} \cdot \mathrm{T}^{*}$

$=10400.0 .274=2849,6$ lembar

\section{Penentuan Model Persediaan yang digunakan}

Untuk menentukan model persediaan yang diusulkan, perlu dilakukan perhitungan total biaya dengan menggunakan hasil dari Economic Order Quantity (EOQ) dan Economic Order Interval (EOI) [7].

1. Model Economic Order Quantity (EOQ)

$$
\begin{aligned}
& \mathrm{TC}=\left(\mathrm{P}_{1} \cdot \mathrm{R}_{1}+\mathrm{P}_{2} \cdot \mathrm{R}_{2}\right)+\mathrm{m}^{*} .\left(\mathrm{C}_{1}+\mathrm{C}_{2}\right)+( \\
& \left.\frac{Q 1 . H 1}{2}+\frac{Q 2 \cdot H 2}{2}\right) \\
& \mathrm{TC}=(\mathrm{Rp} \cdot 2000.1513,5)+(\mathrm{Rp} \cdot 200 . \\
& 10400)+(4 \quad \text { (Rp. } 2.172 .944+ \\
& \text { Rp.2.230.333) })+\left(\frac{414,699 . R p \cdot 31464}{2}+\right. \\
& \left.\frac{2849,6.6742}{2}\right) \\
& =\text { Rp. 38.850.154,2/tahun. }
\end{aligned}
$$

2. Model economic Order Interval (EOI)

$$
\begin{aligned}
& \mathrm{TC}=\left(\mathrm{P}_{1} \cdot \mathrm{R}_{1}+\mathrm{P}_{2} \cdot \mathrm{R}_{2}\right)+\frac{(C 1+C 2)}{T *}+\left(\frac{Q 1 \cdot H 1}{2}+\right. \\
& \left.\frac{Q 2 \cdot H 2}{2}\right) \\
& \mathrm{TC}=(\mathrm{Rp} \cdot 2000 \cdot 1513,5)+(\mathrm{Rp} \cdot 200 \\
& 10400)+\frac{(\mathrm{Rp} \cdot 2 \cdot 172 \cdot 944+\mathrm{Rp} \cdot 2 \cdot 230 \cdot 333)}{0.274} \\
& +\left(\frac{414,699 \cdot R p \cdot 31464}{2}+\frac{2849,6 \cdot 6742}{2}\right) \\
& \mathrm{TC}=\mathrm{Rp} .37 .307 \cdot 402,2 / \text { tahun. }
\end{aligned}
$$

\section{Analisis Rancangan Pengendalian Persediaan}

Analisis mengenai perbandingan total biaya dengan model persediaan yang digunakan dengan sistem yang diterapkan perusahaan, dari perhitungan setiap bahan baku yang telah dilakukan maka didapatkan perbandingan total biaya keseluruhan sebagai berikut :

Tabel 7. Perbandingan lbiaya total persediaan bahan baku antara kondisi aktual perusahaan, model Economic Order Quantity (EOQ) dan Economic Order Interval (EOI) 


\section{JURNAL ILMIAH TEKNIK MESIN, INDUSTRI, ELEKTRO DAN SIPIL}

Rancangan sistem multi item single supplier sebagai pengendali jumlah dan frekuensi pemesanan beberapa bahan baku untuk meminimasi total biaya persediaan

(studi kasus di pt. $x$ )

\begin{tabular}{|c|c|c|c|}
\hline \multirow[t]{2}{*}{ No } & $\begin{array}{l}\text { Aktual } \\
\text { Perusahaan }\end{array}$ & $\begin{array}{l}\text { Economic } \\
\text { Order } \\
\text { Quantity }\end{array}$ & $\begin{array}{l}\text { Econom } \\
\text { Order } \\
\text { Interval }\end{array}$ \\
\hline & $\begin{array}{l}\text { Biaya Kertas } \\
\text { dan Plate }\end{array}$ & $\begin{array}{l}\text { Biaya Kertas } \\
\text { dan Plate }\end{array}$ & $\begin{array}{l}\text { Biaya Ke } \\
\text { dan Plate }\end{array}$ \\
\hline Total & $\begin{array}{l}\text { Rp. } \\
60.921 .473,2\end{array}$ & $\begin{array}{l}\text { Rp. } \\
38.850 .154,2\end{array}$ & $\begin{array}{l}\text { Rp. } \\
37.307 .\end{array}$ \\
\hline $\begin{array}{l}\text { Berdas } \\
\text { model } \\
\text { total b } \\
\text { aktual } \\
\text { Quanti }\end{array}$ & $\begin{array}{l}\text { an perbandin } \\
\text { onomic Ord } \\
\text { a yang palir } \\
\text { erusahaan }\end{array}$ & $\begin{array}{l}\text { an total biaya } \\
\text { Interval me } \\
\text { an kecil daripa } \\
\text { an Economic }\end{array}$ & Orde \\
\hline
\end{tabular}

\section{KESIMPULAN}

Kesimpulan yang dapat diambil dari hasil perhitungan yang telah dilakukan adalah sebagai berikut :

1. Metode persediaan bahan baku yang digunakan adalah metode Multi Item Single Supplier dengan model Economic Order Quantity (EOQ) dan model Economic Order Interval (EOI)

2. Metode Multi Item Single Supplier digunakan karena bahan baku kertas dan plate berasal dari supplier yang sama sehingga pemesanan dilakukan secara bersamaan agar dapat meminimasi biaya total yang dikeluarkan dari perusahaan.

3. Model Economic Order Interval (EOI) digunakan pada perhitungan ini karena biaya yang dihasilkan lebih kecil dari model Economic Order Quantity (EOQ) dan biaya aktual perusahaan yaitu Rp. 37.307.402,2
[3] Bahagia,N. S, 2006, System Inventory, ITB, Bandung

[4] Ristono, A., 2007, Manajemen Persediaan, Graha Ilmu, Yogyakarta

5] Nasution, A. H., \& Prasetyawan, Y., 2008, Perencanaan dan Pengendalian Produksi, Graha Ilmu, Yogyakarta.

[6] Tersine, R. J., 1994, Principle of Inventory and Materials Management, Fourth Edition, Prentice Hall.

[7] Turner, W. C., 2000, Pengantar Teknik dan Sistem Industri: Jilid 1, Guna Widya, Surabaya.

\section{DAFTAR PUSTAKA}

[1] Rangkuti, Fredy. 2004. Manajemen Produksi dan Perencanaan Sistem Produksi Buku I, BPPE, Yogyakarta.

[2] Ginting, Rosnani. 2007. Sisem Produksi, Graha Ilmu, Yogyakarta 